\title{
Chemotherapy and management of tuberculosis in the United Kingdom: recommendations of the Joint Tuberculosis Committee of the British Thoracic Society
}

\author{
L P Ormerod for a subcommittee of the Joint Tuberculosis Committee
}

The number of notified cases of tuberculosis in Britain has fallen over the last 10 years but the disease still causes appreciable morbidity and mortality. ${ }^{12}$ There have been major changes in the staffing of thoracic medicine over the same period since the retirement of many physicians with long experience of tuberculosis. The treatment of tuberculosis depends not only on the correct prescription of effective chemotherapy. regimens but also on the patient's compliance with treatment. Several studies have shown that when treatment is not supervised by thoracic physicians prescription errors and excessive or inadequate treatment occur in an appreciable proportion of patients. ${ }^{3-5}$ The patient's compliance is a major determinant of the success of drug treatment, and is more likely to be achieved if the most effective and shortest regimens are prescribed correctly, with treatment monitored, and adjusted if necessary, by an experienced physician. Recent studies have shown problems of compliance and default $\left(10^{\circ}{ }_{0}\right)$ and drug toxicity $\left(10^{\circ}{ }_{0}\right)$ in adult patients in England and Wales. ${ }^{6}$

In view of the development of effective short course regimens and major changes in the staffing of the services that provide tuberculosis treatment, the Joint Tuberculosis Committee of the British Thoracic Society believes that it is now opportune to issue guidelines for the management of tuberculosis in the United Kingdom. Guidelines have been published recently by the American Thoracic Society $^{7}$ and by the International Union against Tuberculosis and Lung Diseases. ${ }^{8}$ The committee considers that treatment of all cases of adult pulmonary tuberculosis should be supervised by physicians in thoracic medicine, and that the drug treatment of all forms of adult non-pulmonary tuberculosis should at the very least be supervised in conjunction with a thoracic physician. The treatment of children should be shared by a paediatrician and a thoracic physician.

\section{Recommended regimens for adults} PULMONARY TUBERCULOSIS

A six month regimen, comprising rifampicin, isoniazid, pyrazinamide and ethambutol for the initial two months, followed by rifampicin and isoniazid for a further four months, is recommended standard treatment for adult pulmonary tuberculosis irrespective of the bacteriological state of the sputum. There is evidence that the fourth drug (ethambutol) can be omitted in patients with a low risk of resistance to isoniazid. ${ }^{910}$ This applies to previously untreated patients in Britain.

\section{NON-PULMONARY TUBERCULOSIS}

Although there have been relatively few controlled clinical trials in non-pulmonary tuberculosis, the evidence suggests that it can be treated with the same regimens as pulmonary disease. ${ }^{11}$ The duration of chemotherapy for some forms of extrapulmonary tuberculosis (described below*), may need to be longer than six months.

\section{Meningitis *}

Isoniazid and pyrazinamide penetrate into the cerebrospinal fluid well ${ }^{12}$; rifampicin penetrates less well. Streptomycin and ethambutol do so only in adequate concentrations when the meninges are inflamed at an early stage of treatment. Intrathecal administration of any drug is unnecessary. Experience in centres treating large numbers of cases suggests that rifampicin and isoniazid for 12 months supplemented by pyrazinamide for at least the first two months will give good results. ${ }^{11}$ Corticosteroids are recommended in more severe disease (stage II or $\mathrm{III}^{11}$ ).

\section{Lymph nodes *}

The British Thoracic Society trial showed that a nine month course of rifampicin and isoniazid is as effective as an 18 month course if combined with ethambutol for the first two months. ${ }^{13}$ If pyrazinamide is given for the first two months instead of ethambutol, it may be possible to reduce the total duration of treatment to six months. This is currently under investigation in a further British Thoracic Society trial. The course of lymph node disease is variable; abscesses may form, nodes may enlarge, or new nodes may develop during or after treatment, without any evidence of 
Table 1 Recommended treatment

\begin{tabular}{|c|c|c|c|c|c|}
\hline & \multicolumn{2}{|c|}{ Initial phase } & \multicolumn{2}{|c|}{ Continuation phase } & \multirow[b]{2}{*}{ Total months } \\
\hline & Drugs & Months & Drugs & Months & \\
\hline \multirow{7}{*}{$\begin{array}{l}\text { ADULTs } \\
\text { Pulmonary } \\
\text { Non-pulmonary } \\
\text { Meningitis } \\
\text { Pericarditis } \\
\text { Lymph node } \\
\text { Bone, joint } \\
\text { Other sites }\end{array}$} & & & & & \\
\hline & R H Z E & 2 & R H & 4 & 6 \\
\hline & R H Z & 2 & R H & 10 & 12 \\
\hline & RHZE & 2 & $\mathrm{RH}$ & 4 & 6 \\
\hline & R H Z & 2 & R H & 4 & 6 \\
\hline & R H Z E & 2 & R H & 4 & 6 \\
\hline & R H E & 2 & $\begin{array}{l}\text { or } \\
\mathrm{R}_{\mathrm{H}}\end{array}$ & 7 & 9 \\
\hline \multirow{2}{*}{$\begin{array}{l}\text { CHILDREN } \\
\text { Pulmonary }\end{array}$} & & & & & \\
\hline & R H Z & 2 & $\begin{array}{l}\mathrm{R} \mathrm{H} \\
\text { or }\end{array}$ & 4 & 6 \\
\hline \multicolumn{6}{|l|}{$\begin{array}{l}\text { Non-pulmonary } \\
\text { (as above) }\end{array}$} \\
\hline Chemoprophylaxis & $\begin{array}{l}\mathrm{H} \\
\mathrm{R}_{\mathrm{H}}\end{array}$ & $\begin{array}{l}6 \\
3\end{array}$ & & & $\begin{array}{l}6 \\
3\end{array}$ \\
\hline
\end{tabular}

R-rifampicin; H-isoniazid; E-ethambutol; Z-pyrazinamide.

bacteriological reactivation of disease. They do not therefore in isolation imply failure of treatment.

Bone and joints *

The spine is the most common bony site of tuberculosis. Multicentre trials have shown that ambulatory chemotherapy is highly effective in disease of the thoracic and lumbar spine. Recent studies have confirmed that nine months' treatment with rifampicin and isoniazid with or without initial streptomycin gives good results. ${ }^{114}$ Although these studies did not include pyrazinamide, the nine month regimen with two months' pyrazinamide is likely to give equally good results for tuberculosis of bones and joints, and six months' treatment might be just as effective. Surgery may be required in a few patients with evidence of spinal cord compression.

\section{Pericarditis}

A six month regimen of rifampicin and isoniazid, supplemented with streptomycin and pyrazinamide for three months, has been shown to be highly effective, ${ }^{15}$ and the six month regimen recommended for pulmonary disease is likely to be equally effective. The same trial also showed clear additional benefit from high dose corticosteroid treatment in active constrictive pericarditis, ${ }^{15}$ and the same has been shown for pericardial effusion. ${ }^{16}$

Other sites, including genitourinary tract

The six month regimen for pulmonary disease is recommended. If pyrazinamide is omitted or cannot be tolerated treatment should be extended to a total of nine months.

As with pulmonary disease, the committee strongly recommends that drug treatment should be determined by a thoracic physician and preferably also supervised by that physician and supporting services.

The recommended drug regimens are summarised in table 1 .

\section{Chemotherapy for children}

It is important that wherever possible a paediatrician and thoracic physician should be concerned in the treatment of children. Although there is very little research on chemotherapy in children the same basic principles of chemotherapy are considered to apply. Higher dosages (in relation to body weight) of certain drugs have been recommended, but there is now evidence that $10 \mathrm{mg} / \mathrm{kg}$ of both rifampicin and isoniazid are sufficient (table 2). Pyrazinamide is used throughout the world in children, and is recommended for use by the American Thoracic Society ${ }^{7}$ and the International Union against Tuberculosis and Lung Diseases. ${ }^{8}$ Because of the difficulties of testing eyesight and of obtaining reports of visual symptoms in young children, ethambutol should be used only in exceptional circumstances-for example, in the presence of drug resistance or drug toxicity. Dosages should be rounded up or down to facilitate the prescription of easily given volumes of syrup or appropriate strengths of tablet; the dosage may need to be revised with weight gain.

For pulmonary disease the six month regimen of rifampicin and isoniazid, supplemented by pyrazinamide for the first two months, is recommended. No routine pyridoxine supplement is needed if isoniazid is given in standard dosage (table 2). If pyrazinamide is not given the duration of treatment should be extended to nine months. Non-pulmonary disease should be treated by the same regimens as in adults (see above).

Table 2 Recommended dosage

\begin{tabular}{|c|c|c|c|c|c|c|}
\hline \multirow[b]{3}{*}{ Drug } & \multicolumn{3}{|l|}{ Daily dosage } & \multicolumn{3}{|c|}{ Intermittent dosage } \\
\hline & \multirow{2}{*}{$\begin{array}{l}\text { Children } \\
\text { (mg/kg) }\end{array}$} & \multicolumn{2}{|l|}{ Adults } & \multirow{2}{*}{$\begin{array}{l}\text { Children } \\
\text { (mg/kg) }\end{array}$} & \multicolumn{2}{|l|}{ Adults } \\
\hline & & Weight & Dose & & Weight & Dose \\
\hline Isoniazid & 10 & - & $300 \mathrm{mg}$ & $\begin{array}{l}15 \\
3 \text { times weekly }\end{array}$ & - & $\begin{array}{l}15 \mathrm{mg} / \mathrm{kg} \\
3 \text { times weekly }\end{array}$ \\
\hline Rifampicin & 10 & $\begin{array}{l}<50 \mathrm{~kg} \\
\geqslant 50 \mathrm{~kg}\end{array}$ & $\begin{array}{l}450 \mathrm{mg} \\
600 \mathrm{mg}\end{array}$ & $\begin{array}{l}15 \\
3 \text { times weekly }\end{array}$ & - & $600-900 \mathrm{mg}$ \\
\hline Pyrazinamide & 35 & $\begin{array}{l}<50 \mathrm{~kg} \\
\geqslant 50 \mathrm{~kg}\end{array}$ & $\begin{array}{l}1.5 \mathrm{~g} \\
2.0 \mathrm{~g}\end{array}$ & $\begin{array}{l}50 \\
3 \text { times weekly } \\
75 \\
2 \text { times weekly }\end{array}$ & $\begin{array}{l}<50 \mathrm{~kg} \\
\geqslant 50 \mathrm{~kg} \\
<50 \mathrm{~kg} \\
\geqslant 50 \mathrm{~kg}\end{array}$ & $\begin{array}{l}2.0 \mathrm{~g} \\
2.5 \mathrm{~g} \\
3.0 \mathrm{~g} \\
3.5 \mathrm{~g}\end{array}$ \\
\hline & $15-20$ & $\begin{array}{l}<50 \mathrm{~kg} \\
\geqslant 50 \mathrm{~kg}\end{array}$ & $750 \mathrm{mg}$ & $\begin{array}{l}15-20 \\
3 \text { times weekly }\end{array}$ & $<50 \mathrm{~kg}$ & $750 \mathrm{mg}$ \\
\hline Ethambutol ${ }^{\star}$ & $\begin{array}{l}25 \text { for } 2 \text { months } \\
\text { then } 15 \\
\text { or } \\
15 \\
\text { throughout }\end{array}$ & $25 \mathrm{~m}$ & $\begin{array}{l}2 \text { months } \\
\mathrm{ng} / \mathrm{kg} \\
/ \mathrm{kg} \\
\text { hout }\end{array}$ & $\begin{array}{l}30 \\
4 \text { times weekly } \\
25 \\
2 \text { times weekly }\end{array}$ & $\begin{array}{l}30 \mathrm{mg} / \mathrm{kg} \\
3 \text { times weekly } \\
45 \mathrm{mg} / \mathrm{kg} \\
2 \text { times weekly }\end{array}$ & \\
\hline
\end{tabular}

*Accurate calculation is required to avoid toxicity-see under "Special precautions." 


\section{CHEMOPROPHYLAXIS}

Children (under 16)

Children who are found to have a strongly positive tuberculin skin test response but no clinical evidence of disease may need prophylactic treatment. Chemoprophylaxis is recommended if the Heaf test response is positive (grades 2-4) in a person without previous BCG vaccination, and should be considered if the response test is strongly positive (grade 3-4) in someone who has had BCG. ${ }^{17}$ Many studies have shown that 12 months' chemoprophylaxis with isoniazid is effective. ${ }^{18}$ Isoniazid prophylaxis for six months is probably as effective. ${ }^{19}$ Regimens of rifampicin and isoniazid lasting only three months have been used extensively in clinical practice in some areas of the United Kingdom with good effect and no increased adverse reactions. ${ }^{20}$

Treatment with either isoniazid alone for six months or rifampicin and isoniazid for three months are recommended.

Adults

If chemoprophylaxis is considered appropriate for adults, ${ }^{17}$ the same regimens should be used.

\section{Neonates}

Newborn babies of mothers with sputum smear positive pulmonary tuberculosis should be given chemoprophylaxis for three months, followed by BCG vaccination after the completion of chemoprophylaxis, provided that the mother is no longer infectious.

\section{Special groups \\ Diabetes}

Diabetic patients have an increased incidence of tuberculosis, and pulmonary disease is usually more extensive. Standard treatment should be given. Rifampicin interacts with some oral hypoglycaemic drugs.

\section{Liver disease}

Although rifampicin, isoniazid, and pyrazinamide are all potentially hepatotoxic, the addition of pyrazinamide to regimens containing the other two drugs does not increased morbidity. ${ }^{21}$ In patients with pre-existing liver disease standard treatment should be given, but monitoring of liver function in such patients is advised.

\section{Pregnancy}

Standard treatment should be given to pregnant women. Streptomycin and other aminoglycosides should be avoided in pregnancy as they are ototoxic to the fetus. None of the first line drugs has been shown to be teratogenic in man, but ethionamide and prothionamide may be. Patients should be told of the reduced effectiveness of the combined oral contraceptive in regimens containing rifampicin. Should pregnancy occur in patients taking rifampicin, however, it is not an indication for termination. Patients can breast feed normally while taking antituberculous drugs.

Renal disease

Rifampicin, isoniazid, and pyrazinamide can be given in standard dosage in renal failure. If streptomycin or ethambutol is used, reduced dosage is required and serum concentrations should be monitored. Dialysis in patients with chronic renal failure has a considerable effect on the clearance of drugs, and requires modification of dosages. ${ }^{22}$ The dose of any corticosteroids should be doubled if rifampicin is used..$^{23}$

\section{AIDS}

No clinical trial data are available, but it is recommended that standard treatment with four drugs (isoniazid, rifampicin, pyrazinamide, and ethambutol) should be given initially; this may need to continue for longer than standard treatment. ${ }^{24}$ It is also suggested that isoniazid alone should be continued after treatment has been completed. Consideration should be given to isoniazid prophylaxis in HIV positive individuals with a positive tuberculin test response. Non-tuberculous mycobacteria are a common problem in patients with AIDS.

\section{Corticosteroids}

Corticosteroids may be indicated, in addition to effective antituberculosis treatment, in patients with extensive pulmonary disease, tuberculosis affecting the ureter, ${ }^{25}$ pleural effusion, ${ }^{26}$ pericarditis, ${ }^{15}$ and stage II and III meningitis, ${ }^{11}$ and to suppress hypersensitivity reactions.

\section{Non-compliant patients}

Vagrants, alcoholics, and patients who are mentally ill are unlikely to comply with self medication. These, and others found to be noncompliant, are best given fully supervised chemotherapy regimens. Isoniazid, rifampicin, and pyrazinamide with streptomycin or ethambutol three times weekly for two months, followed by rifampicin and isoniazid three times weekly for four months, are recommended (for dosages see table 2).

\section{Unconscious patients}

Standard treatment should be given to unconscious patients, but ethambutol should be omitted as visual acuity cannot be tested. Isoniazid and rifampicin can be given as syrup, and crushed pyrazinamide tablets by nasogastric tube (for dosages see table 2). Alternatively, rifampicin (Rifadin infusion) and isoniazid (Rimifon) can be administered by once daily intravenous infusion. Isoniazid can also be given by intramuscular injection. Streptomycin is given intramuscularly.

\section{Drugs}

Controlled trials of antituberculosis chemotherapy have established a number of highly effective short course regimens in widely varying populations of patients and health services. ${ }^{27}$ As a result of trials and parallel in vivo and in vitro laboratory studies the basic mechanisms of action of the major antituberculosis drugs are better understood. ${ }^{27-29}$ Isoniazid is the most effective bactericidal drug, 
but rifampicin is also important. Rifampicin and pyrazinamide are the most important sterilising drugs and are thought to act by killing different populations of semidormant organisms (persisters). Isoniazid and rifampicin are the most effective drugs at preventing the emergence of resistance to other drugs. ${ }^{27}{ }^{30}$ Streptomycin and ethambutol have been included in the initial phase of many short course regimens but are considered to be of lesser importance in patients with fully sensitive organisms.

The efficacy of short course chemotherapy with a nine month regimen of rifampicin and isoniazid supplemented by two months' initial streptomycin or ethambutol for pulmonary disease in the United Kingdom was shown by studies carried out by the British Thoracic and Tuberculosis Association. ${ }^{31} 32$ Several studies have shown that six month regimens were also highly effective provided that pyrazinamide was added in the initial two months of treatment. $^{2133-35}$ The need for the fourth drug (streptomycin or ethambutol) in the initial phase of chemotherapy for fully sensitive organisms has been questioned. Trials in Singapore ${ }^{9}$ and Poland ${ }^{10}$ have shown no loss of efficacy if streptomycin is omitted. The same is probably true of ethambutol, which is a less potent antituberculosis drug. In Britain daily unsupervised drug treatment is used almost invariably. ${ }^{2131}$ In other parts of the world regimens that are either partially or wholly intermittent have been shown to be highly effective. Thus the alternatives of daily treatment throughout the six months, daily treatment for two months followed by treatment two or three times weekly for four months, ${ }^{89}$ or treatment two or three times weekly for six months ${ }^{36}$ have all been shown to be highly effective. The dosages of antituberculosis drugs for daily and intermittent use are set out in table 2 . All drugs should be given in a single daily dose. It should be noted that for some of the drugs used in intermittent treatment the dosages are higher than those for daily use (table 2).

\section{Adverse reactions}

All the antituberculosis drugs may occasionally cause adverse reactions. Surveys of the results of antituberculosis treatment given in Britain ${ }^{637}$ have shown that treatment required modification for drug toxicity in an appreciable proportion of patients. The most important adverse reactions and interactions are set out below (for full details of all possible adverse reactions the appropriate data sheet should be consulted).

\section{Isoniazid}

Cutaneous hypersensitivity

Peripheral neuropathy (preventable by pyridoxine $10 \mathrm{mg}$; this is advised for those at risk of neuropathy-for example, diabetic and alcoholic patients and those with chronic renal failure or malnutrition) Hepatitis-less common. ${ }^{21}$

Interactions: Anticonvulsant effects may be potentiated (phenytoin, ethosuximide, carbamazepine).

\section{Rifampicin \\ Hepatitis $^{21}$ \\ Rash \\ Gastrointestinal upset.}

With intermittent or irregular treatment a "flu like" syndrome with abdominal and respiratory symptoms may occur; these resolve if treatment is given daily. Shock, acute renal failure, and thrombocytopenic purpura may occur, usually with intermittent treatment; if so withdraw the drug and do not reintroduce.

Interactions: Induction of microsomal hepatic enzymes-reduced serum half life and therefore efficacy of warfarin, phenytoin, sulphonylureas, oestrogen oral contraceptives, corticosteroids. Corticosteroid dose should be doubled. ${ }^{23}$

\section{Ethambutol}

Dose related optic neuropathy; rare at $15 \mathrm{mg} / \mathrm{kg}$.

Patients should be warned to stop the drug immediately if any visual symptoms occur and report to the physician. Avoid the drug whenever possible in patients with reduced renal function and young children, and in anyone with pre-existing visual impairment.

\section{Streptomycin \\ Giddiness}

Rash (hypersensitivity)

Avoid in babies, the elderly, and patients with reduced renal function or pregnancy.

\section{Pyrazinamide \\ Initial facial flushing \\ Rash \\ Nausea \\ Anorexia \\ Vomiting \\ Arthralgia \\ Raised serum uric acid (may be overcome by intermittent dosage) \\ Hepatitis. $^{21}$}

\section{Special precautions and pretreatment screening}

Renal function should be checked before treatment with steptomycin or ethambutol. If possible the drugs should be avoided in renal failure, but if they are used serum concentrations should be monitored and substantially reduced dosages given. Because of the possible (but rare) toxic effects of ethambutol on the eye, it is recommended that visual acuity should be tested by Snellen chart before it is used. ${ }^{38}$ The drug should be used only in patients who have reasonable visual acuity and who are able to appreciate and report visual symptoms. The notes should record that the patient has been told to report visual symptoms, and the general practitioner should be informed of this. In small children and in those 
with language difficulties ethambutol should be avoided where possible.

Liver function should be checked before treatment. Transient increases in hepatic transaminases are common after the start of treatment, and require no action unless the patient has symptoms of hepatitis or jaundice. After the initial measurement liver function does not need to be monitored routinely except in alcoholics and those with other liver diseases. If jaundice or other symptoms of hepatitis develop, all drugs must be stopped. It is usually possible to restart all drugs after liver function has returned to pretreatment levels. If symptoms recur, however, the drugs should be introduced individually, once liver function has returned to normal, at a lower dose initially together with at least one drug that is unlikely to cause hepatic dysfunction (streptomycin or ethambutol). ${ }^{39}$

\section{Combined drug preparations}

Some combined preparations are available. Mynah (Lederle) contains a combination of ethambutol and isoniazid in various dosages; Rifinah (Merrell) and Rimactizid (CIBA) combine isoniazid and rifampicin; and the newer Rifater (Merrell) combines isoniazid, rifampicin, and pyrazinamide. Combined preparations have the major advantages of aiding compliance and preventing monotherapy. Those containing rifampicin provide a useful means of checking compliance as the urine can be assessed visually or checked in the laboratory for the orange/pink discoloration. The bioavailability of drugs from such combination tablets is similar to that from the same doses of drugs given individually, ${ }^{40}$ and clinical results are satisfactory. ${ }^{41}$ The dosages of isoniazid, rifampicin, and pyrazinamide in some studies of combined preparations ${ }^{4041}$ have varied slightly from the dosages in the currently available Rifater (Merrell) in the UK (50 mg isoniazid, $120 \mathrm{mg}$ rifampicin, and $300 \mathrm{mg}$ pyrazinamide per tablet). These minor variations are unlikely to be clinically important in combined preparations with proved bioavailability. Care must be taken with the writing and dispensing of prescriptions because of the similarity in the names rifampicin, Rifinah, Rimactizid, and Rifater. Similar care must be taken with the calculation of the dose of ethambutol if Mynah is prescribed because of the range of doses.

\section{Clinical management}

The minimum requirements are:

1 Notification

Notification of the index case should be made so that appropriate contact tracing can be arranged. ${ }^{17}$

\section{Treatment}

Most patients do not require admission to hospital, and can be treated and supervised as outpatients. If the patient is admitted to hospital and is smear positive for acid fast bacilli, segregation for reasons of infectivity is required for only two weeks; patients become non-infectious within two weeks of treatment that contains rifampicin and isoniazid. ${ }^{29}$ Follow up should be at least monthly initially and then two monthly, the early follow up being important to reinforce education of the patient. Sputum examination for pulmonary disease should be repeated two months before treatment is due to be stopped if the patient's clinical progress is unsatisfactory or where compliance is in doubt. A chest radiograph should be taken at the end of treatment. Clinic nurses or tuberculosis health visitors are extremely important for monitoring patients' compliance and the accuracy and continuity of prescribing, tablet checks and urine tests for rifampicin being carried out during chemotherapy. Monitoring of non-pulmonary disease is largely based on clinical assessment and radiography where appropriate.

Failure during chemotherapy or a relapse after treatment in patients prescribed effective regimens is almost invariably due to poor compliance (see below).

\section{Drug resistance}

Treatment of patients with drug resistant tuberculosis should be carried out only by a thoracic physician experienced in the management of such cases. Initial drug resistance is now rare in white patients. ${ }^{42}{ }^{43}$ It occurs in $8-13^{\circ}$ of Indian, Pakistani, and Bangladeshi patients, however, $11 \%$ having organisms resistant to stretomycin; but this is not clinically important in the UK because streptomycin is now rarely used. ${ }^{37}$ Six per cent of patients from the Indian subcontinent, however, have resistance to isoniazid, which is highly relevant as it may require a change in treatment. It is particularly important to include ethambutol under these circumstances.

If isoniazid resistance is known before treatment is started, a regimen of streptomycin, pyrazinamide, rifampicin, and ethambutol for two months followed by rifampicin and ethambutol for seven months has been shown to give good results when fully supervised. ${ }^{44}$ If definite pretreatment resistance to isoniazid is reported after the start of chemotherapy isoniazid may be stopped, but ethambutol ( $15 \mathrm{mg} / \mathrm{kg}$ ) should be given with rifampicin for a minimum of 12 months, together with two months' initial pyrazinamide, although there is evidence that the regimen may be effective without this. ${ }^{45}$

In cases of multiple drug resistance affecting both rifampicin and isoniazid, treatment should be started with at least three drugs to which the organism is sensitive and continued until sputum cultures become negative, after which two drugs should be continued for at least nine months more. Treatment in such patients has to be planned on an individual basis, ${ }^{30}$ and may need to include reserve drugs (table 3). Such treatment must be closely monitored, as full compliance is essential to prevent the emergence of further drug resistance.

\section{After treatment}

Relapse is uncommon in the United Kingdom with the recommended regimen $(0-3 \%$ of 
Table 3 Reserve drugs: dosages and side effects

\begin{tabular}{|c|c|c|c|c|}
\hline \multirow[b]{3}{*}{ Drug } & \multicolumn{3}{|c|}{ Daily dosage } & \multirow[b]{3}{*}{ Main side effects } \\
\hline & \multirow{2}{*}{$\begin{array}{l}\text { Children } \\
\text { (mg/kg) }\end{array}$} & \multicolumn{2}{|l|}{ Adults } & \\
\hline & & Weight & Dose & \\
\hline Thiacetazone & 4 & - & $150 \mathrm{mg}$ & $\begin{array}{l}\text { Gastrointestinal, rash, } \\
\text { vertigo, conjunctivitis }\end{array}$ \\
\hline $\begin{array}{l}\text { Ethionamide }^{\star} \text { and } \\
\text { prothionamide } \\
\text { PAS }\left(\text { sodium) }^{\star}\right.\end{array}$ & $\begin{array}{l}15-20 \\
300\end{array}$ & $\begin{array}{l}<50 \mathrm{~kg} \\
\geqslant 50 \mathrm{~kg} \\
-\end{array}$ & $\begin{array}{c}750 \mathrm{mg} \\
1.0 \mathrm{~g} \\
10-15 \mathrm{~g}\end{array}$ & $\begin{array}{l}\text { Hepatitis, } \\
\text { gastrointestinal } \\
\text { Gastrointestinal, } \\
\text { rash, hepatitis }\end{array}$ \\
\hline $\begin{array}{l}\text { Kanamycin }{ }^{\dagger} \\
\text { Capreomycin } \\
\text { Cycloserine }{ }^{\dagger}\end{array}$ & $\begin{array}{l}10-15 \\
15 \\
15\end{array}$ & $\begin{array}{l}- \\
- \\
<50 \mathrm{~kg} \\
\geqslant 50 \mathrm{~kg}\end{array}$ & $\begin{array}{l}\text { Divided doses } \\
500 \mathrm{mg}-1 \mathrm{~g} \\
1 \mathrm{~g} \\
750 \mathrm{mg} \\
1 \mathrm{~g}\end{array}$ & $\begin{array}{l}\text { See streptomycin } \\
\text { See streptomycin } \\
\text { Depression, fits }\end{array}$ \\
\hline
\end{tabular}

^Not currently available in the UK

$\dagger$ Adults only.

PAS-para-aminosalicylic acid.

cases) if there is good compliance with treatment. ${ }^{35}$ If compliance has been good and there are no residual clinical problems no follow up is required, but the patient should be advised to return if symptoms recur. Relapse after recommended chemotherapy when compliance is good is almost always with fully sensitive organisms and can be treated with the same regimen. If poor compliance is thought to be a factor in relapse, a fully supervised regimen should be considered. The development of acquired drug resistance should be treated as in (3) above.

The organisational framework for the monitoring of tuberculosis treatment already exists in local thoracic medical clinics with trained doctors and nurses. Treatment is therefore most appropriately supervised by thoracic physicians.

1 Humphries MJ, Byfield SP, Darbyshire JH, et al. Deaths occurring in newly notified patients with pulmonary tuberculosis in England and Wales. Br J Dis Chest 1984 78:149-58.

2 Howie VK, Forbes GI, Urquhart JD. The Scottish respiratory tuberculosis survey. London: HMSO, 1982 (Reports 11 and 12)

3 Wardman AG, Williams SE, Curzon PDG, Page RL, Cooke NJ. Tuberculosis: who should prescribe? $\mathrm{Br}$ Med 1982;284:569-71.

4 Monie RDH, Hunter AM, Rocchiccioli K, White J, Campbell IA, Kilpatrick GS. Survey of pulmonary tuberculosis in south and west Wales $(1976-8)$. Br Med J 1982;284:571-3

5 Monie RDH, Hunter AM, Rocchiccioli K, White J, Campbell IA, Kilpatrick GS. Management of extrapulmonary tuberculosis (excluding miliary and meningeal) in south and west Wales (1976-8). Br Med J 1982;285:415-8.

6 Medical Research Council Tuberculosis and Chest Diseases Unit. Treatment of pulmonary tuberculosis in patients notified in England and Wales in 1978-9: chemotherapy and hospital admission. Thorax 1985;40:113-20.

7 American Thoracic Society. Treatment of tuberculosis and tuberculosis infection in adults and children. Am Rev tuberculosis infection in ad

8 Committee on Treatment of the International Union against Tuberculosis and Lung Disease. Antituberculosis regimens of chemotherapy. Bull IUAT Lung Dis 1988 63(No 2):60-4.

9 Singapore Tuberculosis Service and British Medical Research Council. Clinical trial of three 6-month regimens of chemotherapy given intermittently in the continuation phase in the treatment of pulmonary tuberculosis. Am Rev Respir Dis 1985;132:374-8.

10 Snider DE, Graczyk DE, Bek E, Rogowski J. Supervised six-months treatment of newly diagnosed pulmonary tuberculosis using isoniazid, rifampin and pyrazinamide with and without Streptomycin. Am Rev Respir Dis 1984;130:1091-4.

11 Girling DJ, Darbyshire JH, Humphries MJ, Sister Gabriel O'Mahoney. Extra-pulmonary tuberculosis. Br Med Bull 1988;44:738-56.

12 Ellard GA, Humphries MJ, Gabriel M, Tech R. Penetration of pyrazinamide into the CSF in tuberculous meningitis. Br Med J 1987;294:284-5.

13 British Thoracic Society Research Committee. Short course chemotherapy for tuberculosis of lymph nodes; a controlled trial. Br Med J 1985;290:1106-8.

14 MRC Working Party on Tuberculosis of the Spine. A controlled trial of 6-month and 9-month regimens of chemotherapy in patients undergoing radical surgery for tuberculosis of the spine in Hong Kong. Tubercle 1986;67:243-59

15 Strang JIG, Kakaka HHS, Gibson DG, Girling DJ, Nunn $\mathrm{AJ}$, Fox W. Controlled trial of prednisolone as adjuvant in treatment of tuberculous constrictive pericarditis in Transkei. Lancet 1987;ii:1418-22.

16 Strang JIG, Kakaza HH, Gibson DG, et al. Controlled clinical trial of complete open surgical drainage and of prednisolone in treatment of tuberculous pericardial effusion in Transkei. Lancet 1988;ii:759-63.

17 Joint Tuberculosis Committee of the British Thoracic Society. Control and prevention of tuberculosis: an updated code of practice. 1990. Br Med J 1990;300:995-8.

18 Ferebee SH. Controlled chemoprophylaxis trials in tuberculosis. A general review. Adv Tuberc Res 1970;17: 28-104.

19 Thomson NJ. Efficacy of various durations of isoniazid preventive therapy in tuberculosis: 5 years of follow-up in the IUAT trial. Bull WHO 1982;60:555-64.

20 McNicol MW, Thompson H, Riordan JF, Forde E, Allen $\mathrm{CJ}$. Antituberculous chemotherapy with isoniazid-rifampicin [abstract]. Thorax 1984;39:223-4.

21 British Thoracic Association. A controlled trial of 6-months chemotherapy in pulmonary tuberculosis. First report: results during chemotherapy. $\mathrm{Br} J$ Dis Chest 1981;75: 141-53.

22 Anonymous. Tuberculosis in patients having dialysis [editorial]. Br Med J 1980;i:349.

23 Edwards OM, Courtney-Evans RJ, Galley JM, Hunter J, Tait AD. Changes in cortisol metabolism following rifampicin therapy. Lancet 1974;ii:549-51.

24 Goldman KP. AIDS and tuberculosis. Br Med J 1987; 295:511-2.

25 Horne NW, Tulloch WS. Conservative management of renal tuberculosis. Br J Urol 1975;47:481-7.

26 Horne NW. A critical evaluation of corticosteroids in tuberculosis. Adv Tuberc Res 1966;15:1-54

27 Girling DJ. The chemotherapy of tuberculosis. In: Ratledge C, Stanford J, Grange JM, eds. Biology of mycobacteriaclinical aspects of mycobacteria. Vol 3. London: Academic Press, 1989:285-323.

28 Mitchison DA. Treatment of tuberculosis. $J R$ Coll Physicians 1980;14:91-9.

29 Jindani A, Aber VR, Edwards EA, Mitchison DA. The early bactericidal activity of drugs in patients with pulmonary bactericidal activity of drugs in patients with pulm
tuberculosis. Am Rev Respir Dis 1980;121:139-48.

30 Anonymous. Chemotherapy of pulmonary tuberculosis in Britain. Drug Ther Bull 1988;26:1-4.

31 British Thoracic and Tuberculosis Association. Shortcourse chemotherapy in pulmonary tuberculosis. Lancet 1976;ii:1102-4.

32 British Thoracic Association. Short-course chemotherapy in pulmonary tuberculosis. Lancet 1980;i:1182-3.

33 Singapore Tuberculosis Service and British Medical Research Council. Clinical trial of six-month and fourmonth regimens of chemotherapy in the treatment of pulmonary tuberculosis. The results up to 30 months. Tubercle 1981;62:95-102.

34 East and Central African and British Medical Research Council. Controlled clinical trial of 4 short-course regimens of chemotherapy (three six-month and one eight-month) for pulmonary tuberculosis. Tubercle 1983;64:153-66.

35 British Thoracic Society. A controlled trial of 6-months chemotherapy in pulmonary tuberculosis. Final report: results during the 36 months after the end of chemotherapy and beyond. BrJ Dis Chest 1984;78:330-6.

36 Prabhakar R. Fully intermittent six-month regimens for pulmonary tuberculosis in South India. In: Proceedings of the XXVI World IUAT Conference, Singapore, 1986. Tokyo: Professional Postgraduate Services Japan, 1987: 21-3.

37 Darbyshire JH, Byfield SP, Nunn AJ, Citron KM, Fox W. Results of treatment of adults with pulmonary tuberculosis in England and Wales notified in 1983. Thorax 1987;42:222-8.

38 Citron KM, Thomas GO. Ocular toxicity from ethambutol. Thorax 1986;41:737-9.

39 Citron KM, Girling DJ. Tuberculosis. In: Weatherall DJ, Ledingham JGG, Warrell DA, eds. Oxford textbook of
medicine. 2nd ed. Oxford: Oxford Medical Publications, medicine. 2nd ed. Ox
1987:295 (section 5).

40 Ellard GA, Ellard DR, Allen BW, et al. The bioavailability of isoniazid, rifampin and pyrazinamide in two commercially available combined formulations designed for use in the short-course therapy in tuberculosis. Am Rev Respir Dis 1986;133:1076-80.

41 Geiter LJ, O'Brien RJ, Combs DL, Snider DE. United States Public Health Service tuberculosis therapy trial 21. Preliminary results of an evaluation of a combination tablet of isoniazid, rifampin and pyrazinamide. Tubercle 1987;68:41-6.

42 Medical Research Council Tuberculosis and Chest Diseases Unit. A national survey of tuberculosis notifications in England and Wales 1978-9. Br Med J 1980;281:895-8.

43 Medical Research Council Tuberculosis and Chest Diseases Unit. National survey of notifications of tuberculosis in England and Wales 1983. Br Med J 1985;291:658-61.

44 Babu Swai O, Alnoch JA, Githui WA, et al. Controlled clinical trial of a regimen of 2 durations for the treatment of clinical trial of a regimen of 2 durations for the treatment of
isoniazid resistant tuberculosis. Tubercle 1988;69:5-14.

45 Mitchison DA, Nunn AJ. Influence of initial drug resistance on the response to short-course chemotherapy in pulmonary tuberculosis. Am Rev Respir Dis 1986;133 